American Journal of Pharmaceutical Education 2016; 80 (9) Article 150.

\title{
RESEARCH
}

\section{First-Year Pharmacy Students' Views on Their Chosen Professional Career}

\author{
Lezley-Anne Hanna, PhD, Fergal Askin, MPharm, Maurice Hall, PhD \\ Queen's University Belfast, School of Pharmacy, Northern Ireland, United Kingdom \\ Submitted August 16, 2015; accepted November 10, 2015; published November 25, 2016.
}

Objective. To investigate what factors influenced students to study pharmacy and determine in which sector they hoped to gain employment, both in the short and longer term.

Methods. First-year pharmacy students $(n=124)$ were invited to complete a paper-based, selfadministered questionnaire consisting of 4 sections. Descriptive statistics and nonparametric tests were conducted.

Results. One hundred (96.8\% response rate) students completed the questionnaire $(22.5 \%$ male; $77.5 \%$ female). Key influential factors for choosing pharmacy included: enjoyment of science at school, a desire to improve people's health and wellbeing, and to work in health care. Career aspirations were to work in a hospital or in community practice rather than in industry or academia.

Conclusions. Students choose pharmacy as a career primarily for altruistic and clinical reasons. This research provides information for pharmacy schools about the career aspirations of students and data from future pharmacists is potentially helpful to pharmacy professional organizations and potential employers.

Keywords: career choice; pharmacy students; questionnaire

\section{INTRODUCTION}

There are various reasons why individuals choose a particular career path. For example, contributing to healthcare and enjoying science-based subjects at school have been cited when choosing pharmacy. ${ }^{1-3}$ Status and a high income have been reported to be more important to dental students than medical students. ${ }^{4}$ Moreover, studies within pharmacy, medicine, and dentistry have reported that gender is a factor that affects career choice. ${ }^{3,5-7}$

The majority of research relating to pharmacy students has been conducted mainly in the United States. ${ }^{2,8-12}$ However, there is a need for more up-to-date studies in the United Kingdom to further expand the field, particularly because pharmacy has evolved to be more patientfocused and service-driven than was previously the case. Moreover, stimulating students' interest in pharmacy is of utmost importance for universities and pharmacy professional bodies to facilitate advancement of the profession across the world. ${ }^{13}$ Also, in some regions (for example, across Europe) there is an ongoing shortfall of pharmacists for various reasons such as an aging population and greater pharmacist involvement in clinical services such as chronic disease management. ${ }^{14}$ Awareness of motivational factors

Corresponding Author: Lezley-Anne Hanna, School of Pharmacy, Queen's University Belfast, 97 Lisburn Road, BT9 7BL, Northern Ireland, UK. Tel: +44(0)289-0972-731. Fax: +44(0)289-024-7794. E-mail: 1.hanna@qub.ac.uk could enhance student recruitment strategies and ensure that students have an accurate perception of their chosen profession. Indeed, the Accreditation Council for Pharmacy Education (ACPE) in the United States mentions the need for recruitment policies as part of their accreditation standards document for doctor of pharmacy (PharmD) degree programs. ${ }^{15}$ Moreover, the General Pharmaceutical Council, which is the United Kingdom's accrediting body for master of pharmacy (MPharm) degree programs, discusses recruitment and the provision of career advice. ${ }^{16}$

We wanted to investigate Queen's University Belfast (QUB) Level 1 (also known as first-year students) MPharm students' views on their career choice. The objectives were to investigate what factors influenced students to study pharmacy and determine in which sector they hoped to gain employment, both in the short and longer term. Comparisons were conducted to ascertain whether gender and country where students received their education affected responses.

\section{METHODS}

Data were collected using a paper-based, selfadministered questionnaire (available from the author by request), developed with reference to the wider literature. ${ }^{1-11}$ The survey instrument was relatively short (12 discrete questions) and items were largely in a closed-question format to maximize the response rate. ${ }^{17}$ There were four sections relating to: influences when deciding to study pharmacy, views 


\section{American Journal of Pharmaceutical Education 2016; 80 (9) Article 150.}

on chosen career, career aspirations, and nonidentifiable demographic information. Responses to the majority of questions were based on a 5-point rating scale ranging from $5=$ very important to $1=$ not important) and a 5 -point Likert scale ranging from $5=$ strongly agree to $1=$ strongly disagree).

Several open response items were included on the questionnaire. A cover sheet outlined the purpose of the study, gave a predicted completion time, and provided assurance that participation was voluntary. The questionnaire was first pilot tested by 10 postgraduate pharmacy students and assessed for face validity by 2 academic staff members. The study population was Level 1 pharmacy students enrolled in the MPharm degree program at QUB $(\mathrm{N}=124)$. The students were invited to complete the questionnaire during a compulsory workshop in February 2015. No follow-up invitation to complete the questionnaire (second distribution) was issued as we predicted that most students would be present in the obligatory class. Each student could only complete the questionnaire once.

Responses were coded and entered into SPSS for Windows, version 20 (IBM, New York) for statistical analysis. Analyses mainly took the form of descriptive statistics and, as the data were not normally distributed, nonparametric tests were employed to test for associations between responses for gender and education (European Union [EU] educated versus non-EU educated), with $p<0.05$ set as significant a priori.

Ethical approval for this study was obtained from the QUB School of Pharmacy Ethics Committee.

\section{RESULTS}

A response rate of $96.8 \%$ was obtained. In terms of demographic information, $22.5 \%$ of participants were male and $77.5 \%$ were female. The mean age of participants was 19.2 years (range 18-29 years). Eighty-one $(67.5 \%)$ of the 120 students received their undergraduate education in Europe, while 32.5\% received their undergraduate education elsewhere. The European-educated students $(n=81)$ encompassed students who reported being educated in the United Kingdom or Ireland. The remainder of respondents (39) reported being educated in Asia (38), including in Brunei, Hong Kong, Malaysia, Indonesia, Iran, or in Africa (1 reported being educated in Kenya). As the response rate was close to $100 \%$, the demographic profile of the respondents (the sample) was almost identical to that of the entire Level 1 cohort.

The top 3 influential factors for choosing pharmacy (as determined by students' scores for each factor) were: enjoyment of science at school, a desire to improve people's health and well-being, and a desire to work in healthcare. There were 6 significant differences $(p<0.05)$ found when gender and place of education (European vs nonEuropean) comparisons were conducted. Table 1 provides comprehensive information on all factors, corresponding students' scores, and $p$ values for the gender and education comparisons.

The other reason why students chose to study pharmacy was failure to get accepted into a medicine degree course ( 7 students reported this via the open-response aspect of the questionnaire).

The majority $(89.2 \%)$ of respondents strongly agreed or agreed that they were looking forward to a career in pharmacy. Interestingly, $69.1 \%$ of European-educated students strongly disagreed or disagreed that they would choose a different degree program if applying again compared with $35.9 \%$ non-European educated students $(p<0.001)$. Moreover, $60.0 \%$ of respondents indicated that their opinions of pharmacy as a career choice had changed since starting the program, largely because they were unaware of the extent and variety of roles in pharmacy prior to entering the program.

Almost a third of respondents $(30 \%)$ would consider pursuing a more advanced degree upon finishing the master's pharmacy program. Furthermore, the open response question in this section of the questionnaire revealed that since starting the pharmacy degree program, students had a greater awareness of possible career pathways within pharmacy (22 students reported this) and a better appreciation of the role of the pharmacist ( 9 students reported this).

Figure 1 outlines the short- and longer-term career aspirations of the respondents. Short term refers to immediately following registration (also known as licensing), whereas longer term refers to 10 years post-registration. As seen in Figure 1, the biggest change in terms of shortand longer-term goals was the shift from being a community pharmacy employee to an employer. The gender and education comparisons yielded no significant differences. Finally, the open response questions in this section of the questionnaire revealed that in the short term, 1 student wished to pursue a career in the defense forces, while 2 students reported longer-term career aspirations to work in the fields of dentistry and cosmetic pharmacy, respectively.

\section{DISCUSSION}

Students' reasons for choosing pharmacy centered on their enjoyment of science at school, the ability to improve people's health and well-being, and a desire to work in healthcare. The majority of students were looking forward to a career in pharmacy. Only a small proportion were undecided as to what sector they would like to work in; short- and long-term aspirations centered on hospital and community practice rather than academia or industry. 
American Journal of Pharmaceutical Education 2016; 80 (9) Article 150.

Table 1. Pharmacy Students' Scoring a of the Impact of Various Factors on Their Career Choice

\begin{tabular}{lccccccr}
\hline Factors & All & Male & Female & $\boldsymbol{P}$ value & EU educated & Non-EU educated & $\boldsymbol{P ~ v a l u e ~}^{\mathbf{b}}$ \\
\hline Careers advice from school & 3.3 & 3.3 & 3.3 & .974 & 2.9 & 4.1 & $<.001$ \\
Careers advice from universities & 3.9 & 3.8 & 3.9 & .458 & 3.8 & 3.9 & .594 \\
Self-directed careers advice & 4.3 & 4.1 & 4.3 & .416 & 4.3 & 4.1 & .264 \\
Enjoyed studying science during & 4.8 & 4.8 & 4.8 & .781 & 4.8 & 4.8 & .295 \\
$\quad$ secondary education & & & & & & & \\
Influence of family & 3.6 & 3.3 & 3.7 & .490 & 3.4 & .1 & .088 \\
Influence of friends & 2.6 & 2.6 & 2.6 & .753 & 2.4 & 2.9 & .016 \\
Experience of working in a pharmacy & 3.8 & 3.4 & 3.9 & .052 & 3.9 & 3.8 & .882 \\
Experience of being a pharmacy customer & 3.3 & 2.7 & 3.6 & .002 & 3.0 & 3.8 & .001 \\
Desire to work with people & 4.6 & 4.1 & 4.7 & .002 & 4.7 & 4.5 & .338 \\
Desire to work in the healthcare sector & 4.7 & 4.3 & 4.8 & .002 & 4.7 & 4.8 & .629 \\
Desire to provide public service & 4.3 & 4.0 & 4.4 & .081 & 4.2 & 4.5 & .406 \\
Desire to improve people's health and & 4.8 & 4.5 & 4.8 & .028 & 4.7 & 4.9 & .187 \\
$\quad$ wellbeing & & & & & & & \\
Degree leads to a recognised job & 4.5 & 4.5 & 4.5 & .833 & 4.5 & 4.5 & .425 \\
Professional status & 4.2 & 4.1 & 4.3 & .507 & 4.0 & 4.6 & .009 \\
Salary & 4.1 & 4.2 & 4.0 & .646 & 3.9 & 4.5 & $<.001$ \\
Desire to run a business & 2.9 & 3.1 & 2.8 & .170 & 2.7 & 3.3 & .008 \\
Job security & 4.2 & 4.3 & 4.2 & .782 & 4.0 & 4.4 & .050 \\
Regular working hours & 4.1 & 3.8 & 4.2 & .017 & 4.2 & 4.0 & .241 \\
Flexible working hours & 4.0 & 3.6 & 4.1 & .044 & 3.8 & 4.2 & .081 \\
Independence: can be my own boss & 3.7 & 3.8 & 3.6 & .866 & 3.7 & 3.5 & .648 \\
Range of possible careers within pharmacy & 4.4 & 4.4 & 4.4 & .632 & 4.5 & 4.2 & .201 \\
\hline Abreving
\end{tabular}

Abbreviations: EU=European Union

${ }^{a}$ The possible scores for each factor ranged from 5 to $1(5=$ very important to $1=$ not important). Scores quoted are interpolated medians

${ }^{\mathrm{b}}$ Analysis conducted by gender and education respectively.

Enjoyment of science during secondary education was an important consideration for the students in this study and has previously been shown to be important within various healthcare disciplines. ${ }^{2-4}$ This finding reinforces the need to promote science-based subjects among schoolchildren and ensure they appreciate the relevance of science within a pharmacy context. Otherwise, the profession risks losing these schoolchildren to other

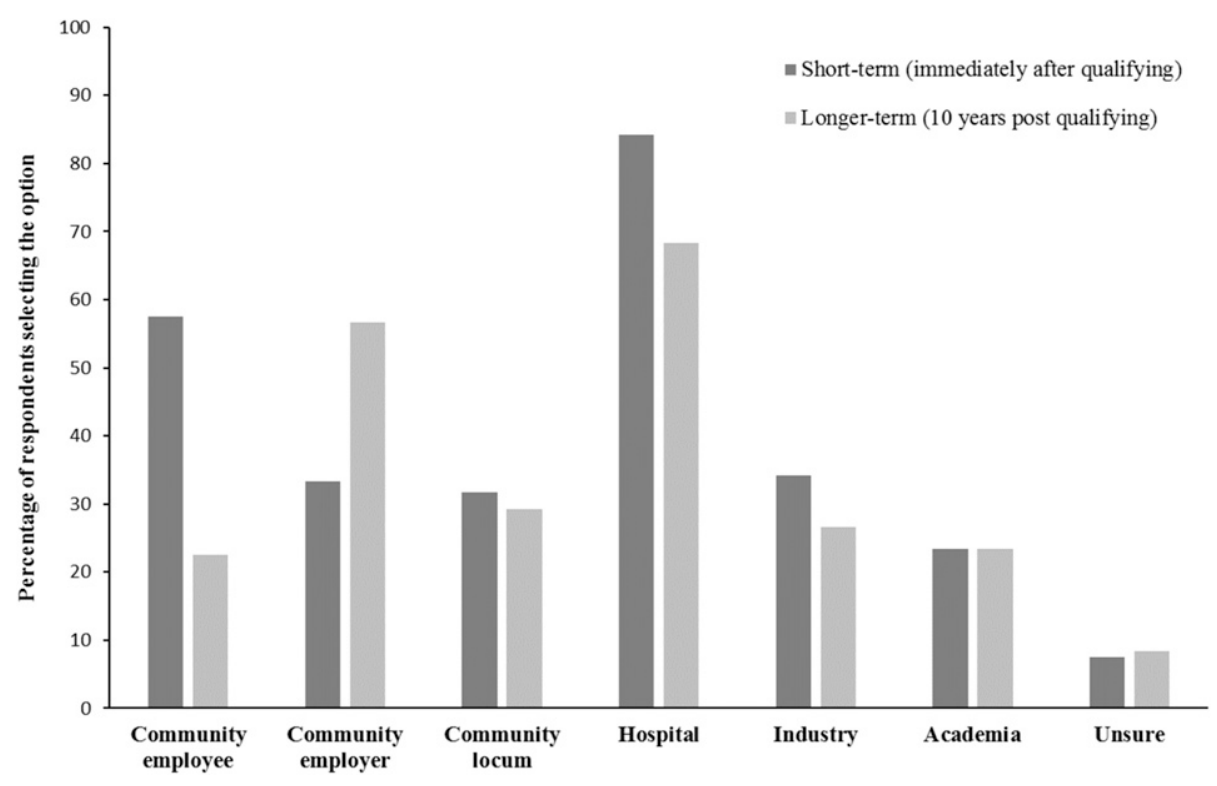

Figure 1. Career aspirations of pharmacy student respondents. 


\section{American Journal of Pharmaceutical Education 2016; 80 (9) Article 150.}

healthcare disciplines. From a pharmacy educator's perspective, it is important to foster this foundational knowledge and passion, given the relevance of science throughout their pharmacy education and beyond.

The desire of the respondents in our study to improve people's health and well-being and wanting to work in the healthcare sector echo the findings of other research. ${ }^{1,4,6,7,18}$ Indeed' in our study, these factors were even more important for female than male students. Pharmacists play a fundamental role in the healthcare of people worldwide. Having a patient-centered attitude coupled with an appreciation of scientific principles is important for future pharmacists and aligns with the vision of the United Kingdom pharmacy professional body ${ }^{19}$ and also the aim of the International Pharmaceutical Federation to "advance pharmacy worldwide." 20

Female respondents were more likely than male respondents to consider work environment factors, namely regular working hours and flexible working hours, to be important, which mirrors the findings from other research $^{18}$ and suggests that female students had already considered how their career would affect their personal life. Savage et al, who conducted research among pharmacy students in the United States, reported that the most important job consideration factors for a career in pharmacy were work environment and benefits. ${ }^{12}$ While it was not a key influential factor overall in this current study, the evolving working environment is something that should be mentioned at recruitment events and throughout the pharmacy degree to ensure that realistic expectations exist.

As the pharmacy profession strives to better integrate pharmacists into multi-professional healthcare teams, a change in work patterns and working environment may occur. For example, pharmacists could be used in accident and emergency departments in England to help address the current staff-to-patient ratio crisis. ${ }^{21}$ Furthermore, the United Kingdom government wants to introduce 7-day access for patients to hospital and general practitioner services, which also could impact working conditions for and contracts with hospital pharmacists. ${ }^{22}$

Salary, status, and a desire to run a business were more important factors for students educated in Asia. Similarly, a survey of pharmacy students in Malaysia (largely Chinese and Malay students), found that salary was an important factor influencing career choice. ${ }^{23}$ Similarly, a survey of final-year pharmacy students at a university in Damascus revealed that one of the most important factors influencing students' career choices was income. ${ }^{24}$ Asian Americans also hold salary and status in high regard when choosing a career. ${ }^{25}$

Additionally, research conducted in the United States investigating factors influencing the selection of a major, and comparing views of pharmacy and nonpharmacy undergraduate students, found that factors such as career prestige and earning potential had a greater influence on pharmacy students than on their nonpharmacy counterparts. ${ }^{10}$ Pharmacy salaries do vary widely across the globe (and across the various sectors of pharmacy) ${ }^{26}$ and tend to be lower than that of other healthcare professionals such as dentists and doctors. Ultimately, if students are asking for advice about which country to work in, individual aspects like salary will have to be considered alongside other factors such as the country's health and education systems and cost of living.

Self-directed and university-led career advice obtained higher scores than career advice provided by schools. However, non-European educated students valued career advice from school significantly more that European educated students. Clearly there is a need for widespread provision of contemporary advice (and perhaps more support for school teachers in the British Isles) so that from an early age people have a realistic view of pharmacists' roles and an awareness of possible pharmacy career pathways. In a US study, only a few pharmacy students indicated that their career decision had been influenced by "career day" type events, while significantly more indicated that they had been influenced by encouragement from pharmacists, interaction with pharmacy students, or work experience in a pharmacy. ${ }^{8}$ Perhaps, as part of wider recruitment initiatives, universities could facilitate more work experience opportunities for school children, enabling them to spend time with pharmacist staff members and current students. We have also started encouraging our international students to participate at recruitment events when they return to their home country during vacation time.

With the increasing emphasis on globalization within higher education, it will be imperative to conduct more research in the United Kingdom to explore how culture and ethnicity affect career choices, so that recruitment strategies can be more tailored. For example, a literature review conducted by Osbourne and colleagues over a decade years ago reported that compared with their white peers, Asian students preferred to study for degrees in medicine-related studies, engineering or mathematics. $^{27}$ Additionally, Afro-Caribbean students preferred to pursue degrees in the social sciences. ${ }^{27}$ A more recent study involving both pharmacy and nonpharmacy students $(n=553)$ in one of the most culturally diverse universities in the United States, showed that Asian-American students favored a career in pharmacy more than African-American and Hispanic students did. ${ }^{2}$

Students' short and longer-term career aspirations were broadly similar and particularly favorable for 


\section{American Journal of Pharmaceutical Education 2016; 80 (9) Article 150.}

hospital or community practice. The biggest shift in terms of short- and longer-term goals was from being a community pharmacy employee to an employer, ie, students contemplated a position of greater responsibility only after they had gained several years' experience in the workplace. This seems like a reasonable, if not somewhat naivve, aspiration to have. Moreover, Hasan et al reported that final-year Malaysian pharmacy students considered hospital or community roles as their first career choices after graduation ${ }^{23}$ while Savage et al found that career goals of pharmacy students in the United States focused predominately on positions in the community (working in a pharmacy chain) immediately after graduation, but these goals broadened to positions in hospital and community (chain and independent) pharmacies 5 years postgraduation. ${ }^{12}$

Siracuse et al also found that around two thirds of the 509 American pharmacy student respondents in their study aspired to a career that involved direct patient care. ${ }^{28}$ Other research has revealed that pharmacy students in Syria wanted to pursue careers in either community pharmacy or the pharmaceutical industry. ${ }^{24}$ In our study, there was limited interest in pursuing a career in academia and industry. Similarly, research conducted in Saudi Arabia on pharmacy students revealed that only $17.2 \%$ considered they had the required knowledge and skills to work in the pharmaceutical industry after graduation. ${ }^{29}$ Perhaps making more research projects and experiential opportunities in the pharmaceutical industry available in the undergraduate degree program would stimulate a greater interest in such career pathways among students.

Furthermore, as Sheaffer et al suggest, enabling student participation in teaching may also help nurture a desire in pursuing an academic pharmacy career ${ }^{30}$ and would also fulfil accreditation requirements of peer development and assessment. ${ }^{15,16}$ While the students may not have desired a career in academia, almost one-third of the respondents stated that they would consider pursuing a further degree upon graduating. This is similar to the findings of Migliore and colleagues where approximately $34 \%$ of 1239 recent PharmD graduates indicated a desire to seek an additional degree. ${ }^{10}$

In the United Kingdom's hospital pharmacy sector, additional qualifications are encouraged and linked to career progression. ${ }^{31}$ However, in the community sector, there is currently no defined career structure or recognized framework for postregistration (licensing) development. Furthermore, as Brazeau et al warned, university educators and academics have a responsibility to stimulate intellectual curiosity, otherwise graduates may lose their scholarly attitude as well as any desire to advance science or the profession of pharmacy. ${ }^{32}$
Regarding study limitations, the questionnaire was administered at only one point in time and from one university, therefore the findings may not be generalizable. However, there were similarities between this research and other studies, as outlined throughout the study. Although this research involved pharmacy students in the United Kingdom, we believe this study has international relevance since many of the factors explored are applicable to various healthcare disciplines. Additionally, given the high response rate, the likelihood of nonresponse bias was minimal.

\section{CONCLUSION}

The results of this study provide information for pharmacy schools about the future career goals of students and how existing recruitment strategies could be enhanced and material within the degree program enriched. From a professional and employer standpoint, this research offers useful data from future pharmacists about factors that may help increase retention and improve job satisfaction. Our study is one of only a few conducted among UK pharmacy students. It would be valuable to conduct further research with these students as they progress through the degree program or do something similar with school students when they are applying for university courses.

\section{ACKNOWLEDGMENTS}

We wish to thank the students who participated in this research. The authors declare that they have no conflicts of interest to report.

\section{REFERENCES}

1. Davey A, Evans AM, Stupans I. Pharmacy: factors that influence the choice of career and study options. Pharm Educ. 2006; 6(1): 21-26.

2. Keshishian F, Brocavich JM, Boone RT, Pal S. Motivating factors influencing college students' choice of academic major. Am J Pharm Educ. 2010;74(3):Article 46.

3. Willis SC, Shann P, Hassell K. Who will tomorrow's pharmacists be, and why did they study pharmacy? Pharm J. 2006;277(7410): 107-108.

4. Crossley ML, Mubarik A. A comparative investigation of dental and medical students' motivation towards career choice. Br Dent J. 2002;193(8): 471-473.

5. Borges NJ, Navarro AM, Grover A, Hoban JD. How, when, and why do physicians choose careers in academic medicine? A literature review. Acad Med. 2010;85(4):680-686.

6. Scarbecz M, Ross JA. Gender differences in first-year dental students' motivation to attend dental school. J Dent Educ 2002;66(8): 952-961.

7. Gallagher JE, Patel R, Donaldson N, Wilson NH. The emerging dental workforce: why dentistry? A quantitative study of final year dental students' views on their professional career. BMC Oral Health. 2007;7(1):7. 


\section{American Journal of Pharmaceutical Education 2016; 80 (9) Article 150.}

8. Anderson DC Jr, Sheffield MC. Massey Hill A, Cobb HH. Influences on pharmacy students' decision to pursue a doctor of pharmacy degree. Am J Pharm Educ. 2008;72(2):Article 22. 9. Lobb WB, Shah M, Kolassa EM. Factors influencing the selection of a major: a comparison of pharmacy and nonpharmacy undergraduate students. $J$ Pharm Teach. 2004;11(2):45-64. 10. Migliore MM, Costantino RC, Campagna NA Jr, Albers DS. Educational and career goals of pharmacy students upon graduation. Am J Pharm Educ. 2013;77(9):Article 187.

11. Rascati KL. Career choice, plans, and commitment of pharmacy students. Am J Pharm Educ. 1989;53(3):228-234.

12. Savage LM, Beall JW, Woolley TW. Factors that influence the career goals of pharmacy students. Am J Pharm Educ. 2009;73(2):Article 28. 13. Inoue Y, Takikawa M., Morita Y, Takao K, Kanamoto I, Sugibayashi K. A comparison of pharmacists' role functions across various nations: the importance of screening. Res Social Adm Pharm. 2015. In press.

14. Pharmacy Workforce 2015. The Pharmaceutical Group of the European Union. http://www.pgeu.eu/policy/14-pharmacyworkforce.html. Accessed November 4, 2015.

15. Accreditation Council for Pharmacy Education. Accreditation standards and key elements for the professional program in pharmacy leading to the doctor of pharmacy degree. Draft standards 2016. https://www.acpe-accredit.org/pdf/ Standards2016DRAFTv60FIRSTRELEASEVERSION.pdf. Accessed August 14, 2015.

16. General Pharmaceutical Council. Future pharmacists: standards for the initial education and training of pharmacists. 2011. https:// www.pharmacyregulation.org/sites/default/files/Standards $\% 20$ for $\%$ 20the $\% 20$ initial $\% 20$ education $\% 20$ and $\% 20$ training $\% 20$ of $\%$ 20pharmacists.pdf. Accessed August 14, 2015.

17. Oppenheim AN. Questionnaire Design, Interviewing and Attitude Measurement. New Edition. New York, NY: Pinter Publishers; 1992.

18. Shen G, Fois R, Nissen L, Saini B. Course experiences, satisfaction and career intent of final year pre-registration Australian pharmacy students. Pharm Pract (Granada). 2014;12(2):Article 392. 19. Smith J, Picton C, Dayan M. Now or never: shaping pharmacy for the future - the report of the Commission on future models of care delivered through pharmacy 2013, Royal Pharmaceutical Society. https://www.rpharms.com/promoting-pharmacy-pdfs/moc-reportfull.pdf. Accessed August 14, 2015.
20. Ongoing projects 2015, International Pharmaceutical Federation. http://www.fip.org/fip_home. Accessed August 14, 2015.

21. Robinson S. Pharmacists set to be drafted into dozens of A\&E departments in England. Pharm J. 2015;294(7847):Uri 20067663.

22. Responding to new announcements by Jeremy Hunt on sevenday working and transparency 2015, Nuffield Trust. http://www. nuffieldtrust.org.uk/media-centre/press-releases/responding-newannouncements-jeremy-hunt-seven-day-working-and-transpare? gclid=CM7ZjKulpscCFe-WtAodDEIESQ. Accessed August 14, 2015.

23. Hasan SS, Kwai Chong DW, Ahmadi K, et al. Influences on Malaysian pharmacy students' career preferences. Am J Pharm Educ. 2010;74(9):Article 166.

24. El-Hammadi M. Career preferences of Syrian students and their attitudes toward a number of practice areas: will community pharmacy continue to dominate the profession? Curr Pharm Teach Learn. 2013;5(5):373-380.

25. Song C, Glick JE. College attendance and choice of college majors among Asian-American students. Soc Sci Q. 2004;85 (5):1401-1421.

26. Best countries for pharmacists to work 2013, Pacific Prime. http://www.rxeconsult.com/healthcare-articles/Best-Countries-forPharmacists-to-Work-484/. Accessed November 14, 2016.

27. Osborne J, Simon S, Collins S. Attitudes towards science: a review of the literature and its implications. Int J Sci Educ. 2003; 25(9):1049-1079.

28. Siracuse MV, Schondelmeyer SW, Hadsall RS, Schommer JC. Assessing career aspirations of pharmacy students. Am J Pharm Educ. 2004;68(3):Article 75.

29. Bin Saleh G, Rezk NL, Laika L, Ali A, El-Metwally A.

Pharmacist, the pharmaceutical industry and pharmacy education in Saudi Arabia: a questionnaire-based study. Saudi Pharm J. 2015;23 (5):573-580.

30. Sheaffer EA, Brown BK, Byrd DC, et al. Variables impacting an academic pharmacy career choice. Am J Pharm Educ. 2008;72(3):

Article 49.

31. Job profiles: hospital pharmacist. Prospects. http://www. prospects.ac.uk/hospital_pharmacist_training.htm. Accessed August 14, 2015.

32. Brazeau GA, Meyer SM, Belsey M, et al. Preparing pharmacy graduates for traditional and emerging career opportunities. Am J Pharm Educ. 2009;73(8):Article 157. 